\title{
Interactions between radiotherapy and endocrine therapy in breast cancer
}

\author{
$R$ del Moral, M E López, M I Núñezi', F J Oliver², M T Valenzuela', \\ $M$ Villalobos ${ }^{1}$ and $J M$ Ruiz de Almodóvar ${ }^{1}$
}

\author{
Servicio de Oncología Radioterápica, Hospital Universitario Virgen de las Nieves, Granada, Spain \\ ${ }^{1}$ Unidad Mixta de Investigaciones Médicas, Hospital Clínico San Cecilio, Departamento de Radiología, \\ Universidad de Granada, Granada, Spain \\ ${ }^{2}$ Instituto de Parasitología y Biomedicina, López Neyra, Consejo Superior de Investigaciones Científicas, \\ Granada, Spain \\ (Requests for offprints should be addressed to J M Ruiz de Almodóvar, Departamento de Radiología, Facultad \\ de Medicina, Universidad de Granada, 18071 Granada, Spain; Email: jmrdar@ugr.es)
}

\begin{abstract}
Whenever radiation therapy is given with curative intent there is the risk of serious damage to normal tissue. This risk increases with the dose of radiation, as does the probability of local tumour control. In the attempt to cure, the doses reach a level that inevitably causes some undesirable adverse effects, ranging from undetectable, or minimal, to unacceptably severe. Over the last few years, a number of reports have suggested that the prediction of normal tissue response after radiotherapy may be achieved by assays on samples withdrawn from the patients prior to treatment, although recent reports have described mixed results. The ability to predict tumour response to anti-hormones in patients with breast cancer has important implications with regard to treatment. Recent discoveries promise to provide individualized treatment options. However, there are no data to support that, used jointly, the combination of radiotherapy and hormone therapy may achieve an enhancement of breast cancer tumour response. Nowadays, development in cancer therapy is increasingly arising out of studies in basic science; its implementation in the hands of clinicians is improving the management of patients with cancer. In addition, as the biological aspects of irradiation and hormonal therapy offer an explanation, at least in part, for the outcome observed in patients with breast cancer after therapy, we have focused this review on trying to analyse the most relevant experimental research about the relative roles of radiotherapy and hormonal therapy, the corresponding side-effects and, taking into account recent advances, future areas of research that we consider of major importance in the field.
\end{abstract}

Endocrine-Related Cancer (2002) 9 197-205

\section{Introduction}

Breast cancer is a very heterogeneous disease in which oestrogen acts as an endocrine growth factor in at least one-third of breast cancer cases and the effects are mediated via the oestrogen-receptor (ER) pathway. The huge differences in the biological characteristics found in the study of patients with breast cancer, including data from clinical, pathological, cellular and molecular studies, are sufficient to explain the dramatic changes, and the diversity, in the treatments recommended over the past two decades. It is well known that prognosis factors influence therapeutic conduct and, based on them, clinical trials have been performed in order to decide treatment, dose and the optimum sequence of different therapeutic agents to be used. The problems of defining the best therapy are immense and clearly this is an important area for research in future.

Tumour size, lymph node status, histological type and grade, oestrogen and progesterone receptors and patient age are accepted as established prognostic and predictive factors valid for the selection of treatment of patients with breast cancer (Albain et al. 1994, Zavagno et al. 2000). The role of other promising new factors, such as $\mathrm{p} 53$, bcl-2, bax, the truncated form of epidermal growth factor receptor gene (ERB-2), alone and/or in association with other factors to define the patho-biological profile of the tumours, could represent an initial framework for a biologically tailored therapy (Ross \& Fletcher 1999, Daidone et al. 2000, Ziyaie et al. 2000, Bièche et al. 2001), the importance of which will be determined in ongoing prospective studies.

The natural history of breast cancer is characterized by an initial stage of sensitivity to medical treatments whereas, at later stages, sometimes even without the previous use of anti-oestrogen or chemotherapeutic agents, the tumour becomes resistant to these growth-inhibitory agents. 
Although mastectomy remains the most frequently used treatment in the early stages, the demand for conservative surgical measures, with or without adjuvant therapy, is growing among women with breast cancer, and many studies indicate that such an approach is adequate for a large subgroup of these patients (Jha et al. 2001). Since there are no clear differences in survival, especially in non-invasive breast cancer in which $95 \%$ or more of the patients are cured no matter how they are treated, we need to consider the fact that individual patients differ in the importance they place on the risk and benefits of adjuvant treatments. In addition, given that the gradually increasing success of cancer treatment has led to longer patient survival which unfortunately implies a greater opportunity for late effects to appear, increasing in severity and impact on quality of life, this parameter might be evaluated after treatment (Amichetti et al. 1999) to provide better ways to support shared decision making between patients and their physicians (Eifel et al. 2001).

Women with primary invasive breast cancer receive both local and systemic treatment. Surgery and radiation therapy are local treatments to reduce the risk of recurrent cancer in the breast, chest wall and regional lymph nodes. Cytotoxic chemotherapy and hormonal therapy are systemic treatments given after local treatment to reduce systemic recurrences and overall mortality from breast cancer. Nonetheless, the management of this class of tumour is a continuing challenge because of the high local recurrence rates and poor survival due to metastatic disease (Tan et al. 2001).

A number of patient and tumour characteristics, which are present at the time of primary cancer diagnosis, affect the subsequent risk of local and distal recurrences. However, the predictive use of one individual characteristic is not straightforward because of interaction with other patients features, tumour and treatment factors but it is clear that locoregionally recurrent breast cancer is an independent predictor of subsequent distant metastasis (Clemons et al. 2001). To identify properly, by means of multivariate analysis, the major factors determining the risk of tumour progression, and to include them in a prognosis index for survival would indeed be useful.

Nowadays, development in cancer therapy is increasingly arising out of studies in basic science; its implementation in the hands of clinicians is improving the management of patients with cancer. In addition, as the biological aspects of irradiation and hormonal therapy offer an explanation, at least in part, for the outcome observed in patients with breast cancer after therapy, we have focused this review on trying to analyse the most relevant experimental research on the relative roles of radiotherapy and hormonal therapy, the corresponding side-effects and, taking into account recent advances, future areas of research that we consider of major importance in the field.

\section{Radiation damage to DNA}

DNA represents the most important target for radiation action on a cell, and subsequently on the tumour and its surrounding normal tissues. A therapeutic dose of low-linear energy transfer (LET) radiation causes a large number of ionizations in every cell. Some of these directly damage DNA; others generate free radicals that react with DNA. Free radicals are extensively scavenged by compounds containing (-SH) sulphydryl groups. Lesions in DNA are very effectively repaired by enzymatic reactions. Some of them fail to repair and become fixed, and any differences in induction and/or repair among double-strand breaks will lead to differences in cell lethality (Steel et al. 1989, Ruiz de Almodóvar et al. 1994, Núñez et al. 1995), but there are many sources of evidence in the sense that DNA damage is the critical event in radiation-induced cell death (Yasui et al. 2001).

The cellular microenvironment of tumours influences their responsiveness to therapeutic agents. None of them is simpler than oxygen, although a host of chemical and pharmacological agents that modify the biological effects of ionizing radiation have been discovered. Considerable controversy surrounds the interpretation of radiosensitivity data from steroid hormones and anti-hormones on oestrogensensitive breast cancer (Sarkaria et al. 1994, Villalobos et al. 1996, Amorino et al. 2000). Currently, our understanding about the mechanisms of radiation-induced cell death in hormone-dependent tumour cells is limited (Siles et al. 1998).

Apoptosis is obviously an important process in biology but, in tumour cells, which have lost the normal interrelationship of cell proliferation and cell death, an in-depth analysis of these two processes would facilitate the design of more effective treatment strategies using radiation therapy alone or combined with other therapeutic modalities. Some authors have pointed out that hormonal treatment might alter the radiation sensitivity in breast cancer regardless of the receptor status, suggesting that hormonal agents may act both via receptor- and non-receptor-binding mechanisms (Wazer et al. 1991, Paulsen et al. 1996).

The importance of cell cycle control in the cell response to DNA-damaging agents is widely accepted and many genes, or the pharmacological modulation of their functionality, might be a critical determinant of cellular radiosensitivity, with a possible differential effect in tumours with non-functional p53 and normal tissues (Valenzuela et al. 2000).

The tumour suppressor protein p53 plays a key role in the cell's decision to arrest the cell cycle or undergo apoptosis following a genotoxic insult (Siles et al. 1996). The presence of damaged DNA in the cell activates the repair mechanisms as well as the signal transduction pathways, leading to cell cycle arrest and repair or apoptosis. Several of these responses are mediated by the stabilization and activation of $\mathrm{p} 53$. It is there- 
fore crucial to understand the events from the initial radiationinduced DNA damage to p53 activation.

bcl-2 protein is a potent anti-apoptotic protein that inhibits a mitochondria-operated pathway of apoptosis in many cells. DNA damage agents and death receptor ligands can activate this mitochondrial mechanism and it has been suggested that the enhanced expression levels of bcl-2 present in tumour cells can render these cells less sensitive, not only to chemotherapeutic drugs but also to tumour necrosis factor-related apoptosis-inducing ligand (Ruiz de Almodóvar et al. 2001). Poly (ADP-ribosylation) of different nuclear acceptors by poly (ADP-ribose) polymerase-1 (PARP-1) is an early event in that cascade; although the nature and the consequence of this interaction are still very controversial, it seems that PARP-1 partially contributes to radiation-induced cell death (Valenzuela et al. 2002).

\section{Tumour and normal tissue response to radiation treatment}

Genetic, epigenetic and nutritional variables have been invoked to explain variations in the intrinsic radiosensitivity of both human tumour and normal tissue cells. Nowadays, it is recognized that these differences exist and that they may be related to the clinical ability to cure and tolerance to treatment. The success of radiotherapy depends on the total radiation dose. In an attempt to cure, the doses reach a level that inevitably cause some collateral side-effects. With each new patient, the radiation oncologist pays attention to those aspects that can be controlled as plans for the treatment of the malignant disease are made; however, there are no ways of accounting for tumour and normal tissue sensitivities which might be the major determinant of successful treatment.

The dilemma for the physician is how to protract the treatment in a way that maximizes control of the tumour and minimizes normal tissue injury. Thus, the tolerance of the normal tissues encompassed within the treatment volume is the factor that limits the dose (Withers 1992). Radiation therapy is associated with a broad spectrum of normal tissue acute and late reactions, ranging from undetectable or minimal to unacceptably severe (Tucker et al. 1992, Burnet et al. 1998). Although a significant proportion of this variation can be attributed to treatment-related factors, there is an increasing evidence showing that the major determining differences are related to intrinsic biological factors (Safwat et al. 2002).

Over the last few years, a number of important publications have suggested that the prediction of normal tissue response after radiotherapy may be achieved by assays performed on cells or tissue samples withdrawn from the patients prior to radiation treatment, although recent reports have described mixed results (Ozsahin et al. 1997, Barber et al. 2000, Peacock et al. 2000, West et al. 2001).
The ability to predict these differences in radiation sensitivity would have important implications with regard to cancer treatment. For example, a strategy based on testing human normal tissue radiosensitivity might permit the individualization of treatment by dose escalation in resistant patients without increasing normal tissue complications (Bentzen 1997). But advocating dose escalation is advocating research that 'is state-of-the-art, not standard of practice' (Glatstein 2001). However, even if an approach to predict in vivo response prior to radiotherapy treatment was validated, clinical implementation would be difficult.

We have previously reported the potential of assays of DNA damage in lymphocytes for this purpose (Núñez et al. 1998), and the existence of an inter-individual variation in the radiosensitivity of normal tissue, measured on lymphocytes as the initial number of DNA double-strand breaks induced by Gy per DNA unit (dsb/Gy per DNA unit). Our results have shown that the radiosensitivity parameter in normal cells can differ by a factor of 10 , ranging from 0.5 to 4.7 dsb/Gy per DNA unit (Ruiz de Almodóvar et al. 2002). Among the patients studied we detected 15 women who developed severe skin reactions. Whether DNA initial radiation-induced damage is related or not to the severity of normal tissue effects after radiation treatment might be better clarified with further research that is currently underway in several centres including our own.

As cancer treatment becomes more effective, more patients survive longer and the importance of short- and long-term morbidity is increased. The categorization of possible side-effects according to a scoring system already shows an improvement in the quality assurance of care and thus in the patients' quality of life. Different scoring protocols are found in the literature. Among them, the European Organization for Research and Treatment of Cancer/Radiation Therapy Oncology group (RTOG) classification (Cox et al. 1995) is a very comprehensive system that deals with both acute and late reactions. Our previous results (López et al. 2002) point out the advantage of the RTOG system over others, at least for evaluating the acute effects produced by radiation treatment on the skin of women with breast cancer.

Clinical oncologists are aware of the fact that late damage is indeed the most important component of morbidity. However, so far, no consistent relationship has been proved between acute and late reactions. Late injury, in particular, represents a threat to normal tissues, either by direct cell death or delayed apoptosis. In both events, the ultimate expression is cell loss and atrophy. Moreover, if enough cells are depleted and not repopulated, there will be a functional organ compromise. Recognition and clearance of apoptotic cells after exposure to radiation produces both a persistent macrophage activation and an inflammatory type response, effects that persist long after the initial radiation insult (Lorimore et al. 2001). 
In breast cancer, the time between the first introduction of new advanced medical tools and the full realization of the potential benefits in the clinic is often quite long, especially considering the long follow-up period required to assess the outcome adequately. The maximum severity of acute effects can be judged during the course of radiotherapy. Late effects would be better judged after 5 years or more. This allows sufficient time for complications to develop fully in some normal tissues, though not in all. The log-normal variation in cellular radiosensitivity among individuals (Ruiz de Almodóvar et al. 2002) could probably be due to polymorphisms of normal genes responsible for processing normal and damaged DNA and/or for chromatin conformation status. In these senses, a single mutated copy of the ataxia telangiectasia gene (ATM) gene occurs in approximately $1 \%$ of the general population; these individuals may be at an increased risk of carcinogenesis or radiosensitivity. It has been described very recently that possession of an ATM mutation may be predictive of an increased rate of subcutaneous late tissue effects after radiotherapy for breast cancer (Iannuzzi et al. 2002).

It seems clear that in order to quantify the relative merits of new treatment modalities or treatment techniques accurately, clinically relevant radiobiological models to predict response are needed. Once accurate genetic- and/or cell survival-based predictive assays become available, radiation therapy will become an exact science allowing truly individual optimization and allow consideration of the various side-effects that the patient is willing to accept (Brahme 2001).

\section{Mechanism and tolerability of hormone therapies in breast cancer}

The normal breast epithelium undergoes cyclical waves of proliferation, differentiation and apoptosis during the menstrual cycles, and after lactation arrest it undergoes remodelling by apoptosis. Factors including oestradiol, progesterone, prolactin, glucocorticoids, insulin, aldosterone, growth factors, as well as contact with the extra-cellular matrix and with the immune system's cells, are all coordinate events that lead finally to mammary epithelium renewal. In the last two decades, studies on breast cancer biology, and relevant information about the biological characteristics of the tumours, have made us aware that in pathological situations many proteins are differently expressed and that they, via cell-type-specific signalling pathways, may contribute to cancer proliferation and tumour progression through the inhibition of apoptosis.

One of the aims of anti-tumour therapy is to obtain tumour regression by inhibiting proliferation and stimulating apoptosis in cancer cells as specifically as possible. One possible way to induce apoptosis in cancer cells is by blocking signal transduction of growth factors and hormone receptors. Apoptosis is a biological event which has been described in experimental systems to be under the control of two main categories of proteins: (a) the bcl-2 family members and (b) the family of cysteinyl aspartate-specific proteases, the caspases. Up to now, at least 13 caspases have been identified in mammalian cells. In experimental models, it has been shown that anti-oestrogen-induced apoptosis is mediated by both caspase-3 and c-jun- $\mathrm{NH}_{2}$-terminal kinase, this mechanism being effective against certain ER-negative tumours (Mandlekar et al. 2000).

Tamoxifen (TAM), a non-steroidal anti-oestrogen, has been used as a treatment for breast cancer for a quarter of a century. A general issue regarding the use of TAM as endocrine therapy is the fact that during long-term treatment drug resistance may occur and that the compound bears the risk of producing second malignancies (Assikis et al. 1996). It is believed that one of the main reasons for these disadvantages is based on the fact that this compound has, besides its antagonist properties, also agonist properties.

In breast cancer, TAM has cytostatic effects mediated through the ER, although functional heterogeneity within populations of cancer cells contributes to seemingly paradoxical effects of anti-oestrogens and the development of anti-oestrogen resistance. In addition, TAM has also been shown to be cytotoxic to both ER-positive and ER-negative cells and such an effect is believed to be mediated by the induction of apoptosis. The cell survival threshold is determined by the balance between cell death-suppressor and cell death-promoter signals provided by external factors or stimuli as well as by intracellular molecules. Proteins of the caspase family are typically present in inactive forms in the cytosol, and are activated by binding to apoptosis-related death receptors or by sequential cleavages. On the other hand, the bcl-2 family of genes has a central role in the control of the response acting either as an apoptosis inhibitor or promoting the cell death programme (Daidone et al. 1999, Lilling et al. 2000, Ruiz de Almodóvar et al. 2001). Despite knowledge about the ER status, it is not always possible to predict which breast cancer will respond to TAM. However, it seems obvious that a relationship between effective TAM therapy and its known anti-proliferative (Danova et al. 1993) and pro-apoptotic actions (Chen et al. 1996) are representative of different mechanisms of tumour response (Cameron et al. 2000). The induction of apoptosis by the compound ICI $128780(\mathrm{ZM})$ is associated with a dramatic decrease in bcl-2 expression (Diel et al. 1999). In cells lacking ER, it has been demonstrated that TAM is able to induced oxidative stress, thereby causing thiol depletion and activating the transcriptional factor nuclear factor $(\mathrm{NF}) \mathrm{KB}$ through the modulation of redox metabolism. Importantly, the induction of apoptosis by TAM is not linked to down-regulation or functional inactivation by phosphorylation of the anti-apoptotic bcl-2 protein (Ferlini et al. 1999). An early event in the induction of apoptosis by TAM involves mitochondrial depolarization and caspase activation that ultimately lead to cellu- 
lar disassembly, and that mechanism occurs independently of p53 (Diètze et al. 2001).

In tumour biopsies, increased bcl-2 expression correlates with the expression of ER, whereas a low expression of bcl-2 characterizes most of Brca-1-associated breast cancer and its down-regulation may account for the increased apoptosis and the high proliferative rate observed in Bcra-1-associated carcinomas (Freneaux et al. 2000).

In summary, effective anti-oestrogen therapy appears to cause tumour regression by two, possibly separate, mechanisms: (a) reducing bcl-2 expression that is associated with increased apoptosis and (b) reducing proliferation with no significant change in Bcl-2 expression. In addition, TAM has recently been suggested to exert an anti-angiogenic effect that contributes to reducing tumour bulk when this drug is used in postmenopausal women with large, operable or locally advanced ER-rich primary breast cancers (Marson $e t$ al. 2001).

There have been several major developments concerning the use of hormonal agents for the treatment of breast cancer over the past few years which impact on current endocrine therapy. Not only we do have a larger number of agents in the clinic, but there has also been a trend to reduced drug toxicity. New treatments are being assessed after surgery, but are also being tested pre-operatively and in combination with radiotherapy and chemotherapy. Among them, endocrine treatments are effective in the following situations. (a) As adjuvant systemic therapies in premenopausal women: these include reducing circulating oestrogen by ablation or by inhibiting ovarian oestrogen production. (b) As adjuvant systemic therapy in postmenopausal women: the mainstay of therapy is the prevention of oestrogen binding to its receptor using an anti-oestrogen or lowering oestrogen levels with aromatase inhibitors. (c) As neoadjuvant systemic therapy in locally advanced breast cancer. (d) As primary treatment for elderly breast cancer patients with locoregional disease and as palliative treatment. (e) For prevention in women with a high risk of developing breast cancer.

Most of our endocrine treatments deprive the tumour cells of oestradiol. New data and the newest treatments available indicate the need to re-think our general approach to endocrine therapy and endocrine prevention (Howell et al. 2001). This is of particular interest today because the results of new combined therapies, including chemotherapy, endocrine therapy and radiotherapy modalities, have also been reported (Crump et al. 1997, Brain et al. 1999, Zambetti et al. 1999, Tan et al. 2001, Vicini et al. 2001).

TAM was introduced more than 20 years ago for the palliative treatment of advanced breast cancer. Response rate to treatment ranges from $20 \%$ to $60 \%$ depending on patient and tumour characteristic and on evaluation stringency. Although this therapy is generally seen as less toxic than many other cancer treatments, it is true that quantifiable data on the side-effects of hormonal therapies such as TAM or goserelin are scarce. A critical review of the published reports describes morbidity in women treated in such a way as minimal or well tolerated, even when accompanied by data suggesting that the majority of patients do experience some undesirable symptoms. Furthermore, TAM is associated with an increased risk of uterine cancer, thromboembolism, hot flushes, sexual dysfunction and cataracts (Fabian \& Kimler 2001) and we need to point out that without good comprehensive morbidity profiles for hormone therapies, prospective patients cannot make informed judgements on proposed treatments (Fellowes et al. 2001).

\section{The objectives of combined therapy}

The biological problems presented by combined radiotherapy and hormone therapy are considerable. Radiotherapy by itself induces complex changes both in tumours and in the adjacent normal tissues. The response to hormone therapy and chemotherapy are similarly complex: in addition to some of the factors that determine the response to radiation treatment we also have problems of drug delivery, drug resistance and metabolism. The combination of radiotherapy and endocrine therapy involves the combined complexity of both modalities, plus the interaction between them. A combination of drugs and radiation can result as non-interactive if each modality appears to exert its own individual effect; interactive refers to a situation where there is evidence that one modality modifies the effect of the other at comparable levels of overall toxicity.

A combination of radiotherapy and hormonal therapy administered sequentially is indeed useful in the management of breast cancer patients and it is supported because (a) radiation is used to treat the primary tumour and endocrine therapy is added as an adjuvant to deal with systemic spread of disease; there might be spatial co-operation between them; (b) although cellular apoptosis may be a common outcome, each one of the two therapeutic modalities might reach this effect through independent mechanisms; (c) both therapies produce changes in the cell cycle distribution that seems to occur by different mechanisms; and (d) collateral side-effects from one or other modality appear different and the possibilities of their being cumulative are poor. A number of clinical trials and a great deal of empirical experience have shown, without any doubt, that both treatments play major roles in breast cancer treatment.

For instance, local control is generally obtained by modified radical mastectomy and radiotherapy on the chest wall, but in a selected subgroup of women, i.e. those with a tumour of limited size without oedema or erythema, conservative surgery may be offered. Apart from the details of dose fractionation, many other factors can influence the incidence and severity of normal tissue reactions. These include concomitant treatment with chemotherapy (Smith \& Lipton 2001). However, other data have pointed out a significant reduction 
in the surgical requirements for mastectomy after treatment with neoadjuvant chemoendocrine therapy, without deterioration in local or distal relapse (Makris et al. 1998), although this treatment has not provided obvious survival benefit to women with breast cancer (Gazet et al. 2001). The need for mastectomy is reduced but not abolished; in some studies this effect is associated with a small increase in the risk of local recurrence (Smith \& Lipton 2001). Post-operative radiotherapy forms an intrinsic part of breast conservation therapy, substantially reducing the risk of breast relapse.

Early complications of radiotherapy include tiredness, skin erythema and moist desquamation but the radiationinduced toxicity on the patients' skin is found with approximately the same frequency regardless of the breast cancer surgical treatment applied. In addition, in our experience, the administration of chemotherapy and concomitant irradiation does not increase the intensity, or its frequency, of the acute adverse effects observed on the skin included in the treatment field (López et al. 2002). However, it is generally accepted that some chemotherapy drugs, including taxanes, may enhance the effectiveness of radiation therapy although they may increase the incidence of radiation pneumonitis (Taghian et al. 2001). Because 5 weeks of whole-breast radiotherapy results in one of the most significant impediments to the widespread use of breast-conserving techniques, acceleration of treatment by confining radiotherapy to the tumour bed has recently been explored. The result of the accelerated treatments using an interstitial implant to deliver radiation to the tumour bed alone over 4-5 days seemed to produce 5-year results equivalent to those achieved with conventional treatment (Vicini et al. 2001). In Vicini et al. (2001), selection criteria were highly restrictive and follow-up was relatively short. Extended follow-up will therefore be required to determine the long-term efficacy of this treatment approach.

Most of the acute side-effects of treatment are reversible, and there is little or no detectable increase in long-term risk of cardiac or lung toxicity or second cancers with the use of current regimens (Lind et al. 2001). An increased incidence of radiation pneumonitis among patients treated with local regional radiotherapy compared with those receiving local radiotherapy only has been reported recently (Lind et al. 2002). Moreover, women treated with breast conservation and post-operative radiotherapy showed a good quality of life with a preserved favourable body image and a lack of negative impact on sexuality. Radiation therapy does not lead to any significant additional problems capable of affecting the quality of life (Amichetti et al. 1999). However, unconventional and more aggressive irradiation protocols are usually associated with the aggravation of acute reactions and it has been noted that a non-healing acute response can directly progress into a late effect; that consequential effects might be minimized by means of the amelioration of the acute response to irradiation (Dörr \& Hendry 2001) and an extended follow-up will be required to determine the longterm efficacy of each new treatment.

Breast cancer research has developed at a rapid pace over the last decades and new options have been evaluated (Tubiana-Mathieu et al. 2001). Recent discoveries promise to provide individualized treatment options. However, there are no data to support that using different treatments jointly might obtain an enhancement of tumour response quantifiable in terms of increase of overall survival with no impairment in the quality of life of the patients. We believe that this, conceptually and experimentally, is a very difficult problem that must first be conducted in experimental models.

\section{Perspectives}

A possible way to progress in basic research with a clear projection to clinical practice is the study of chromatin's conformation and its pharmacological modulation. In the mammalian genome, methylation takes place only at cytosine bases that are located $5^{\prime}$ to a guanosine in a $\mathrm{CpG}$ dinucleotide (Bird 2002). These epigenetic changes, in particular aberrant promoter hypermethylation that is associated with inappropriate gene silencing, affect virtually every step in tumour progression (Jones \& Baylin 2002). DNA methylation is a biochemical modification of chromatin status that can influence gene expression. Our ideas of how DNA methylation is established in the mammalian genome are changing as rapidly as is our understanding of how chromatin organization modulates gene expression.

Very strong evidence accumulated in the past years suggests that cancer cells usurp and use this mechanism to their benefit by inactivating tumour suppressor genes and causing loss of proteins involved in cell cycle regulation, DNA transcription, DNA repair and apoptosis (Santini et al. 2001). This has led to the pursuit of DNA methyl transferase inhibition as a drug target for therapeutic intervention (Bender et al. 1998). Not surprisingly, targeting these pathways often also results in radiosensitization (Pervan et al. 2001), perhaps through the activation of p53 DNA damage response pathway (Karpf et al. 2001) and increases in the amount of DNA radiation-induced damage and impairing cellular repair and recovery.

Loss of expression for both the ER $\alpha$ and E-cadherin genes has been linked to disease progression in human ductal breast carcinomas and has been associated with aberrant 5' CpG island methylation (Nass et al. 2000). Restoration of ER expression could be a strategy to improve the response of the breast negative receptor tumours to treatment with anti-oestrogen. One DNA methyltransferase inhibitor undergoing clinical evaluation is 5 -aza-2'-deoxycytidine (clinical name, decitabine). Taking into account that aberrant methylation occurs in tumours but not in the normal surrounding tissue, this characteristic might be used to improve the clinical outcome of women with breast cancer without increasing 
the associated side-effects. Another drug that inhibits methylation is procainamide, which is used for the treatment of cardiac arrhythmias. This drug is a non-competitive inhibitor of the methyltransferase enzymes and, given the therapeutic promise of reversing methylation changes in cancer, several companies are pursuing this important goal to identify better inhibitors of DNA methylation to be used in clinical studies.

Growing evidence suggests a relationship between alterations in chromatin structure by histone deacetylation and DNA methylation, the development of cancer and higher resistance to treatment. Hopefully, the restoration of chromatin status could provide a modulation in the radiation and hormonal response of tumours (Allan et al. 2000). This approach could be important because combined demethylating agents and histone deacetylase inhibitors induce a 300 to 400 -fold increase in the transcription of ER, suggesting that the activities of both DNA methyl transferase and histone deacetylase are key regulators of methylationmediated ER silencing (Yang et al. 2001). Because ER is a critical growth-regulatory gene in breast cancer, and also a target for anti-oestrogen therapy, is it important to understand its transcriptional regulation better. Whether the pretreatment of breast cancer cells with 5-aza-2'-deoxycytidine sensitizes cells against anti-oestrogen and radiotherapy, enhancing antiproliferative, necrotic and apoptotic cell death, needs to be further investigated.

\section{Acknowledgements}

This work was supported by a grant from the Ministerio de Ciencia y Tecnología, CICYT: SAF 2001-3533 and by the Junta de Andalucía through the project SAS 01/231 to $\mathrm{J}$ M R, by the Fondo de Investigaciones Sanitarias through the project FIS $01 / 1090$ to $\mathrm{M} \mathrm{V}$, and through project FIS 00/ 948 to F J O. M T V is supported by the Instituto de Salud Carlos III (BEFI 009371).

\section{References}

Albain KS, Allred DC \& Clark GM 1994 Breast cancer outcome and predictor of outcome: are there age differentials? Journal of the National Cancer Institute 16 35-42.

Allan LA, Duhig T, Read M \& Fried M 2000 The p21 (WAF1/ CIP1) promoter is methylated in rat-1 cells: stable restoration of p53-dependent p21 (WAF1/CIp1) expression after transfection of a genomic clone containing the p21 (WAF1/CIP1) gene.

Molecular and Cellular Biology 20 1291-1294.

Amichetti M, Caffo O, Arcicasa M, Roncadin M, Lora O, Rignon A, Zini G, Armaroli L, Coghetto F, Zorat P, Neri S \& Teodorani N 1999 Quality of life in patients with ductal carcinoma in situ of the breast treated with conservative surgery and postoperative irradiation. Breast Cancer Research and Treatment 54 109-115.

Amorino GP, Freeman ML \& Choy H 2000 Enhancement of radiation effects in vitro by oestrogen metabolite

2-methoxyestradiol. Radiation Research 153 384-391.
Assikis VJ, Neven P, Jordan VC \& Vergote I 1996 A realistic clinical perspective of tamoxifen and endometrial carcinogenesis. European Journal of Cancer 32A 1464-1476.

Barber JBP, Burrill W, Spreadborough AR, Levine E, Warren C, Kiltie AE, Roberts SA \& Scott D 2000 Relationship between in vitro chromosomal radiosensitivity of peripheral blood lymphocytes and the expression of normal tissue damage following radiotherapy for breast cancer. Radiotherapy and Oncology 55 179-186.

Bender CM, Zingg JM \& Jones PA 1998 DNA methylation as a target for drug design. Pharmacology Research 15 175-187.

Bentzen SM 1997 Potential clinical impact of normal-tissue intrinsic radiosensitivity testing. Radiotherapy and Oncology $\mathbf{4 3}$ 121-131.

Bièche I, Parfait B, Moguès C, Andrieu C, Vidaud D, Spyratos F, Lidereau R \& Vidau M 2001 The CGA gene as a new predictor of the response to endocrine therapy in ER- $\alpha$-positive postmenopausal breast cancer patients. Oncogene 20 6955-6959.

Bird A 2002 DNA methylation patterns and epigenetic memory. Genes and Development 16 6-21.

Brahme A 2001 Individualizing cancer treatment: biological optimisation models in treatment planning and delivery. International Journal of Radiation Oncology-Biology-Physics 49 327-337.

Brain EGC, Misset JL \& Rouëssé J 1999 Primary chemotherapy or hormone therapy for patients with breast cancer. Cancer Treatment Reviews 25 187-197.

Burnet NG, Johansen J, Turensson I, Nyman J \& Peacock JH 1998 Describing patients' normal tissue reactions: concerning the probability of individualising radiotherapy dose prescriptions based on potential predictive assays of normal tissue radiosensitivity. International Journal of Cancer 79 606-613.

Cameron DA, Keen JC, Dixo JM, Bellany C, Hanby A, Anderson TJ \& Miller WR 2000 Effective tamoxifen therapy of breast cancer involves both antiproliferative and pro-apoptotic changes. European Journal of Cancer 36 845-851.

Chen H, Tritton TR, Kenny N, Absher M \& Chiu JF 1996 Tamoxifen induces TGF $\beta 1$ activity and apoptosis of human MCF-7 breast cells in vitro. Journal of Cell Biochemistry $\mathbf{6 1}$ 9-17.

Clemons M, Danson S, Hamilton T \& Goss P 2001 Locoregionally recurrent breast cancer: incidence, risk factors and survival. Cancer Treatment Reviews 27 67-82.

Cox JD, Stetz J\& Pajak TF 1995 Toxicity criteria of the Radiation Therapy Oncology group (RTOG) and the European Organization for Research and Treatment of Cancer (EORTC). International Journal of Radiation Oncology-Biology-Physics 31 1341-1346.

Crump M, Sawka CA, DeBoer G, Buchanan RB, Ingle JN, Forbes J, Meakin JW, Shelley W \& Pritchard KI 1997 An Individual patient based meta-analysis of tamoxifen versus ovarian ablation as first endocrine therapy for premenopausal women with metastatic breast cancer. Breast Cancer Research and Treatment 44 201-210.

Daidone MG, Luisi A, Veroni S, Benini E \& Silvestrini R 1999 Clinical studies of Bcl-2 and treatment benefit in breast cancer patients. Endocrine-Related Cancer 6 61-68.

Daidone MG, Luisi A, Martelli G, Benini E, Veroni S, Tomasic G, De Palo G \& Silvestrini R 2000 Biomarkers and outcome after tamoxifen treatment in node-positive breast cancer from eldery women. British Journal of Cancer 82 270-277. 
Danova M, Pellicciari C, Zibera C, Mangioratti R, Gibelli N, Giordano M, Wang E, Mazzini G \& Riccardi A 1993 Cell cycle kinetics effects of tamoxifen on breast cancer cells. Flow cytometric analyses of DNA content, BrdU labelling, Ki-67, PCNA and statin expression. Annals of the New York Academy of Sciences 698 174-181.

Diel P, Smolnikar K \& Michna H 1999 The pure antioestrogen ICI 182780 is more effective in the induction of apoptosis and down regulation of Bcl-2 than tamoxifen in MCF-7 cells. Breast Cancer Research and Treatment 58 87-97.

Diètze EC, Caldwell E, Grupin SL, Mancini M \& Seewaldt VL 2001 Tamoxifen but not 4-hydroxytamoxifen initiates apoptosis in p53(-) normal human mammary epithelial cells inducing mitochondrial depolarizartion. Journal of Biological Chemistry 276 5384-5394.

Dörr W \& Hendry JH 2001 Consequential late effects in normal tissues. Radiotherapy and Oncology 61 223-231.

Eifel P, Axelson JA, Costa J, Crowley J, Curran WJ Jr, Deshler A, Fulton S, Hendricks CB, Kemeny M, Kornbblith AB, Louis TA, Markman M, Mayer R \& Roter D 2001 National Institutes of Health Consensus Development Conference Statement: adjuvant therapy for breast cancer, November 1-3, 2000. Journal of the National Cancer Institute 93 979-989.

Fabian CJ \& Kimler BF 2001 New endpoint for breast cancer chemoprevention, new drugs for breast cancer prevention. Annals of the New York Academy of Sciences 952 44-59.

Fellowes D, Fallowfield LJ, Saunders CM \& Houghton J 2001 Tolerability of hormone therapies for breast cancer: How informative are documented symptom profiles in medical notes for 'well tolerated' treatments? Breast Cancer Research and Treatment 66 73-81.

Ferlini C, Scambia G, Marone M, Distefano M, Caggini C, Ferrandina A, Isola G, Benedetti Panici P \& Mancuso S 1999 Tamoxifen induces oxidative stress in oestrogen receptor negative human cancer cell lines. Breast Cancer Research and Treatment 79 257-263.

Freneaux P, Stoppa-Lyonnet D, Mouret E, Kambouchner M, Nicolas A, Zafrani B, Vincent-Salomon A, Fourquet A, Magdelenat H \& Sastre-Garau X 2000 Low expression of bcl-2 in Brca-1-associated breast cancer. British Journal of Cancer $\mathbf{8 3}$ 1318-1322.

Gazet JC, Ford HT, Gray R, McConkey C, Sutcliffe R, Quilliam J, Makinde V, Lowndes S \& Coombes RC 2001 Estrogenreceptor-directed neoadjuvant therapy for breast cancer: results of a randomised trial using formestane and methotrexate, mitozantrone and mitomycin C (MMM) chemotherapy. Annals of Oncology 12 685-691.

Glatstein E 2001 Personal thoughts on normal tissue tolerance, or, what the textbooks don't tell you. International Journal of Radiation Oncology-Biology-Physics 51 1185-1189.

Howell A, Howell SJ, Clarke R \& Anderson E 2001 Where do selective oestrogen receptor modulators (SERMs) and aromatase inhibitors (AIs) now fit into breast cancer treatment algorithms? Journal of Steroid Biochemistry and Molecular Biology $79227-$ 237.

Iannuzzi CM, Tencio DP, Green S, Stock RG \& Rosenstein BS 2002 ATM mutations in female breast cancer patients predict for an increase in radiation induced late effects. International Journal of Radiation Oncology-Biology-Physics 52 606-613.

Jha MH, Avlonitis VS, Griffith CD, Lennard TW, Wilson RG, McLean LM, Dawes PD \& Shirimakar J 2001 Aggressive local treatment for screen-detected DCIS results in very low rates of recurrence. European Journal of Surgical Oncology 27 454-458.
Jones PA \& Baylin SB 2002 The fundamental role of epigenetic events in cancer. Nature Reviews Genetics 3 415-428.

Karpf AR, Moore BC, Ririe TO \& Jones DA 2001 Activation of the p53 DNA damage response pathway after inhibition of DNA methyltransferase by 5-Aza-2'-deoxycytidine. Molecular Pharmacology 59 751-757.

Lilling G, Hacohen H, Nordenberg J, Livnat T, Rotter V \& Sidi Y 2000 Differential sensitivity of MCF-7 and LCC2 cells to multiple growth inhibitory agents: possible relation to high bcl-2/bax ratio? Cancer Letters 161 27-34.

Lind PARM, Wennberg B, Gagliardi G \& Fornander T 2001 Pulmonary complications following different radiotherapy techniques for breast cancer, and the association to irradiated lung volume and dose. Breast Cancer Research and Treatment 68 199-210.

Lind PA, Marks LB, Hardenbergh PH, Clough R, Fan M, Hollis D, Hernando ML, Lucas D, Piepgrass A \& Prosnitz LR 2002 Technical factors associated with radiation pneumonitis after local \pm regional radiation therapy for breast cancer.

International Journal of Radiation Oncology-Biology-Physics 52 137-143.

López E, Núñez MI, Guerrero R, del Moral R, Luna JD, Rodríguez MM, Valenzuela MT, Villalobos M \& Ruiz de Almodóvar JM 2002 Breast cancer acute radiotherapy morbidity evaluated by different scoring systems. Breast Cancer Research and Treatment 73 127-134.

Lorimore SA, Coates PJ, Scobie GE, Milne G \& Wright EG 2001 Inflammatory-type responses after exposure to ionising radiation in vivo: a mechanism for radiation-induced bystander effects? Oncogene 20 7085-7095.

Makris A, Powles TJ, Ashley SE, Chang J, Hickish T, Tidy VA, Nash AG \& Ford HT 1998 A reduction in the requirements for mastectomy in a randomized trial of neoadjuvant chemoendocrine therapy in primary breast cancer. Annals of Oncology 9 1179-1184.

Mandlekar S, Yu R, Tse-Hua T \& Kong T 2000 Activation of caspase-3 and c-Jun NH2-terminal kinase-1 signaling pathway in tamoxifene-induced apoptosis of human breast cancer cells. Cancer Research 60 5995-6000.

Marson LP, Kurian KM, Miller WR \& Dixon JM 2001 The effect of tamoxifen on breast tumour vascularity. Breast Cancer Research and Treatment 66 9-15.

Nass DJ, Herman JG, Gabrielson E, Iversen PW, Parl FF, Davidson NE \& Graff JR 2000 Aberrant methylation of oestrogen receptor and E-cadherin 5' CpG islands increases with malignant progresion in human breast cancer. Cancer Research 60 4346-4348.

Núñez MI, Villalobos M, Olea N, Valenzuela MT, Pedraza V, McMillan TJ \& Ruiz de Almodóvar JM 1995 Radiation-induced DNA double-strand break rejoining in human tumour cell lines. British Journal of Cancer 71 311-316.

Núñez MI, Guerrero R, López E, del Moral MR, Valenzuela MT, Siles E, Villalobos M, Pedraza V, Peacock JH, Ruiz de Almodóvar JM 1998 DNA damage and prediction of radiation response in lymphocytes and epidermal skin human cells. International Journal of Cancer 76 354-361.

Ozsahin M, Ozsahin H, Yuquan S, Larson B, Würgler FE \& Crompton NEA 1997 Rapid assay of intrinsic radiosensitivity based on apoptosis in human CD4 and CD8 T-lymphocytes. International Journal of Radiation Oncology-Biology-Physics 38 $429-440$. 
Paulsen GH, Strickert T, Marthinsen AB \& Lundgren S 1996 Changes in radiation sensitivity and steroid receptor content induced by hormonal agents and ionizing radiation in breast cancer cell in vitro. Acta Oncologica 35 1011-1019.

Peacock J, Ashton A, Bliss J, Bush C, Eady J, Jackson C, Owen R, Regan J \& Yarnold J 2000 Cellular radiosensitivity and complication risk after curative radiotherapy. Radiotherapy and Oncology 55 173-177.

Pervan M, Pajonk F, Sun JR \& McBride WH 2001 Molecular pathways that modify tumor radiation response. American Journal of Clinical Oncology 24 481-485.

Ross JS \& Fletcher JA 1999 The HER-2/neu oncogene: prognostic factor, predictive factor and target for therapy. Seminars in Cancer Biology 9 125-138.

Ruiz de Almodóvar JM, Núñez MI, McMillan TJ, Olea N, Mort C, Villalobos M, Pedraza V \& Steel GG 1994 Initial radiation induced DNA damage in human tumour cell lines: a correlation with intrinsic cellular radiosensitivity. British Journal of Cancer 69 457-462.

Ruiz de Almodóvar C, Ruiz-Ruiz C, Muñoz-Pinedo C, Robledo G \& López-Rivas A 2001 The differential sensitivity of Bcl-2-overexpresing human breast tumor cells to TRAIL or doxorubicin-induced apoptosis is dependent on Bcl-2 protein levels. Oncogene 20 7128-7133.

Ruiz de Almodóvar JM, Guirado D, Núñez MI, López MI, Guerrero R, Valenzuela MT, Villalobos M \& del Moral R 2002 Individualisation of radiotherapy in breast cancer patients: possible usefulness of a DNA damage assay to measure normal cell radiosensitivity. Radiotherapy and Oncology 62 327-333.

Safwat A, Bentzen SM, Turesson I \& Hendry JH 2002 Deterministic rather than stochastic factors explain most of the variation in the expression of skin telangiectasia after radiotherapy. International Journal of Radiation Oncology-Biology-Physics 52 198-204.

Santini V, Kantarajian HM \& Issa JP 2001 Changes in DNA methylation in neoplasia: Pathophysiology and therapeutic implications. Annals of Internal Medicine 137 573-586.

Sarkaria JN, Miller EM, Parker CJ, Jordan VC \& Mulcahy RT 1994 4-Hydroxytamoxifen, an active metabolite of tamoxifen, does not alter the radiation sensitivity of $\mathrm{MCF}-7$ breast carcinoma cells irradiated in vitro. Breast Cancer Research and Treatment 30 159-165.

Siles E, Villalobos M, Valenzuela MT, Nuñez MI, Gordon A, McMillan TJ, Pedraza V \& Ruiz de Almodóvar JM 1996 Relationship between p53 status and radiosensitivity in human tumour cell lines. British Journal of Cancer 73 581-588.

Siles E, Villalobos M, Jones L, Guerrero R, Eady JJ, Valenzuela MT, McMillan TJ \& Ruiz de Almodóvar JM 1998 Apoptosis after gamma irradiation. Is it an important cell death modality? British Journal of Cancer 78 1594-1599.

Smith IE \& Lipton L 2001 Preoperative/neoadjuvant medical therapy for early breast cancer. The Lancet Oncology 2 561-570.

Steel GG, McMillan TJ \& Peacock JH 1989 The radiobiology of human cells and tissues. In vitro radiosensitivity: the picture has changed in the 1980s. International Journal of Radiation Biology 56 525-537.

Taghian AG, Assaad SI, Niemerko A, Kuter I, Younger J, Schoenthaler R, Roche M \& Powell SN 2001 Risk of pnuemonitis in breast cancer patients treated with radiation therapy and combination chemotherapy with paclitaxel. Journal of the National Cancer Institute 93 1806-1811.
Tan SM, Cheung KL, Willsher PC, Blamey RW, Chan SY \& Robertson JFR 2001 Locally advanced primary breast cancer: medium-term results of a randomised trial of multimodal therapy versus initial hormone therapy. European Journal of Cancer $\mathbf{3 7}$ 2331-2338.

Tubiana-Mathieu N, Lejeune C, Bonnier P, Genet D, Adjadj DJ, Berda JF, Muracciole X, Delaby F, Clavere P, Benyoub A, Rhein B, Juin B \& Piana L 2001 Chemotherapy and concomitant irradiation in inflammatory breast cancer. Anticancer Research 21 3061-3067.

Tucker SL, Turesson I \& Thames HD 1992 Evidence for individual differences in radiosensitivity of human skin. European Journal of Cancer 28 1783-1791.

Valenzuela MT, Mateos S, Ruiz de Almodóvar JM \& McMillan TJ 2000 Variation in sensitizing effect of caffeine in human tumour cell lines alter $\gamma$-irradiation. Radiotherapy and Oncology 54 261271.

Valenzuela MT, Guerrero R, Núñez MI, Ruiz de Almodóvar JM, Sarker M, de Murcia G \& Oliver FJ 2002 PARP-1 modifies the effectiveness of p53-mediated DNA damage response. Oncogene 21 1108-1116.

Vicini FA, Baglan KL, Kestin LL, Mitchell C, Chem PY, Frazier RC, Edmuinson G, Goldstein NS, Benitez P, Huang RR \& Martínez A 2001 Accelerated treatment of breast cancer. Journal of Clinical Oncology 19 1993-2001.

Villalobos M, Becerra D, Nuñez MI, Valenzuela MT, Siles E, Olea N, Pedraza V \& Ruiz de Almodóvar JM 1996 Radiosensitivity of human breast cancer cell lines of different hormonal responsiveness. Modulatory effects of oestradiol. International Journal of Radiation Biology 70 161-169.

Wazer DE, Joyce M, Solares G \& Schmith-Ulrich R 1991 Proliferative inhibition of human breast carcinoma cells by high concentration estradiol does not alter radiosensitivity. Breast Cancer Research and Treatment 18 141-148.

Withers HR 1992 Biologic basis of radiation therapy. In Principles and Practice of Radiation Oncology, edn 2, pp 64-96. Eds CA Perez \& WB Luther. Philadelphia: Lippincott.

West CML, Davidson SE, Elyan SAG, Valentine H, Roberts SA, Swindel R \& Hunter RD 2001 Lymphocyte radiosensitivity is a significant prognostic factor for morbidity in carcinoma of the cervix. International Journal of Radiation Oncology, Biology, Physics 51 10-15.

Yang X, Phillips DL, Ferguson AT, Nelson WG, Herman JG \& Davidson NE 2001 Synergistic activation of functional oestrogen receptor (ER)- $\alpha$ by DNA methyltransferase and histone deacetylase inhibition in human ER- $\alpha$-negative breast cancer cells. Cancer Research 61 7025-7029.

Yasui LS, Huges A \& Desombre ER 2001 Cytotoxicity of ${ }^{125}$ I-oestrogen decay in non-oestrogen receptor expressing human breast cancer cells, MDA-231 and oestrogen receptor expressing MCF-7 cells. International Journal of Radiation Oncology, Biology, Physics 77 955-962.

Zambetti M, Oriana S, Quattrone P, Verderio P, Terenziani M, Zucali R, Valagusa P \& Bonadonna G 1999 Combined sequential approach in locally advanced breast cancer Annals of Oncology 10 305-310.

Zavagno G, Meggiolaro F, Pluchinotta A, Bozza F, Favretti F, Marconato R, Geraci G, Nistri R, Fontana P, Sorrentino P, Lumachi F, Toniato A, Rossi CR \& Lise M 2000 Influence of age and menopausal status on pathologic and biologic features of breast cancer. The Breast 9 320-328.

Ziyaie D, Hupp TR \& Thompson AM 2000 p53 and breast cancer. The Breast 9 239-246. 